\title{
Self-Esteem and Distress Tolerance of Criminology Students of the University of Bohol
}

\author{
SHIRLEY O. MOLINA \\ http://orcid.org/0000-0001-6346-0053 \\ somolina@universityofbohol.edu.ph \\ MARK JAY O. CELOCIA \\ http://orcid.org/0000-0002-0637-5749 \\ markjaycelocia@yahoo.com \\ JOHN VINCENT D. CUYACOT \\ http://orcid.org/0000-0003-2864-0491 \\ jvkiluacuyacot@yahoo.com \\ CHRISTIAN DELA SERNA \\ http://orcid.org/0000-0003-0961-460X \\ christiandelaserna@yahoo.com \\ JIMBIE A. DELOS SANTOS \\ http://0000-0001-9407-5959 \\ spo2_ds@yahoo.com \\ ALCHITO G. FELICIA \\ http://orcid.org/0000-0002-1033-5811 \\ alchito_felicia@yahoo.com \\ REGINA MAE A. GATAL \\ http://orcid.org/0000-0001-7391-2009 \\ reginamaegatal@gmail.com
}




\section{ABSTRACT}

Self-esteem refers to one's overall evaluation of oneself, while distress tolerance is the ability to withstand pressures and negative emotions. Both constructs have relationships on criminal behaviors based on various studies. The policing profession is one of the most stressful and risky jobs in the whole world, hence, this study aimed to determine the self-esteem level and degree of distress tolerance of Criminology students of the University of Bohol. The research used descriptivequantitative research utilizing two standardized tools, namely, the Rosenberg Self-Esteem Scale and the Distress Tolerance Scale to determine the level of self-esteem of the respondents and to gauge the respondents' degree of tolerance or ability to withstand negative effects or other aversive psychological and or physical states. Purposive sampling was used to get a sample from the total population. The respondents possessed high self-esteem as evidently shown on their mean score of 2.8. As revealed in the data, all the four year levels obtained mean scores falling between the scales of 2.50-3.24 with an interpretation of high self-esteem.

Keywords: Self-esteem, distress tolerance, stress, occupational hazards, criminology, criminal justice, police, University of Bohol

\section{INTRODUCTION}

The policing profession is one of the most stressful and risky jobs in the whole world (Crank and Caldero, 1991; Burke, 1993; Anshel, 2000). According to Forbes Magazine online, policing profession is ranked number five among top ten most stressful jobs in 2015 based on their site ranking (Adams, 2015). This distressing circumstance is apparent in the study of Burke (1989) in America where he said, "police officers reported high rates of marital problems, suicide, alcoholism, and other emotional and health problems."

Meanwhile, in the Philippines, another challenge pressuring its police officers (i.e. Philippine National Police) today is the report of World Nomads and United States Department of State Bureau of Diplomatic Security flagging the entire United States and the whole world about the "moderately high rate of violent crime in the Philippines" (Sylvester, 2015). This identified risk in traveling to the country is the very reason foreigners are advised to be cautious when they 
visit the country.

The research of Elias shows that occupational stress which is inherent to the policing job is one of the contributors to work deviance and other criminal behaviors (Elias, 2013). This factor could be a cause why some police officers in the Philippines are allegedly involved in some misbehavior (e.g., an outburst of anger and physical violence) and are reported to be involved in various crimes like Hulidap and the laglag-bala scheme (BulletPlanting Scam) in Ninoy Aquino International Airport (Tan, 2015).

Interestingly, in the study of Trzesniewski, Donnellan, Moffitt, Robins, Poulton, \& Caspi (2006), it was found out that low self-esteem during adolescence is an important predictor of criminal behavior during adulthood. According to the researchers, adolescents with low self-esteem grow up to have more criminal convictions during adulthood than adolescents with high self-esteem. This result means adolescents who have low selfesteem when they are still young are more likely to commit criminal acts when they become adult.

Cognizant of the challenges in the policing profession and the predisposing factors of police misbehavior and corruption, it is only fitting to ask, "What is the best way to prepare the criminology students to become effective, efficient and morally upright policemen in the future?" The answer lies in the very heart of this research which is self-esteem and distress tolerance. Self-esteem refers to one's overall evaluation of oneself and distress tolerance is the ability to withstand pressures and negative emotions. Both of these constructs have a relationship to criminal behaviors based on various research. As proactive criminology students of the University of Bohol, we are very interested to ascertain if the reported cases abroad are also true in the Philippines, particularly in the City of Tagbilaran.

With firm conviction, the researchers believe that if criminology students' self-esteem and distress tolerance are assessed, it will help not only the College of Criminology of University of Bohol but most especially the students themselves who are vying for a position in the Philippine National Police (PNP). Through this study, the criminology students of the university will become aware of their limitations and weaknesses which is the key towards becoming an emotionally stable, dedicated and morally upright public servants capable of empowering themselves in the face of distress in favor of the higher principles of life. It is in this pursuit that the researchers conducted this study. 
Theories. To reinforce the researchers' study and complement its essential context, the researchers included selective theories which have a strong emphasis on self-esteem and stress.

Hierarchy of Needs Theory. This theory was formulated by an American Humanistic Psychologist Abraham Maslow who theorized that Self-Esteem is one of the basic human needs in order to survive. He wrote that human beings are motivated by five levels of needs - (1) Physiological, (2) Safety, (3) Love and Belongingness, (4) Esteem Needs and (5) SelfActualization. These needs are classified into two, the deficiency and the growth needs. Deficiency Needs such as physiological and safety needs must be met first before human beings can climb to the next level of the pyramid - the growth needs (belongingness, self-esteem, and the highest peak of the pyramid which is self-actualization). If the deficiency needs are not supplied, the person feels deficient and this prevents him from moving up to the next level of the pyramid. This means lower needs must be satisfied first before moving to higher need

The Esteem needs, as one of the higher needs (i.e., growth needs), refer to the need for personal worth, self-respect, self-confidence, mastery, achievement, prestige, and autonomy. These needs are the basis for the people's desire for acceptance. When esteem-needs are satisfied, the person feels confident of himself. He feels valued as a human being. However, when these needs are not reached the person will experience inferiority complex, weakness, helplessness, and worthlessness (Maslow, 1987).

Identity Status Theory. James Marcia, an American clinical and developmental psychologist came up with this theory of psychological identity development. This theory is a refinement and extension of Erikson's fifth level of psychosocial development (i.e. Identity Vs Role Confusion) focusing on the disparity between one's ideal and actual self which can either produce maladaptation or can be a source of aspiration for those who are searching for identity (Marcia, Waterman, Matteson, Archer \& Orlofsky, 1993).

According to Marcia, adolescents develop four recursive identity statuses, namely: (1) Identity Diffusion, (2) Identity Foreclosure, (3) Identity Moratorium, and (4) Identity Achievement. The essence of this theory is that individual's sense of identity is determined by personal choices and commitments made regarding certain personal and social traits (Marcia et al.,1993; Waterman, 1988). 
The following is a collection of readings from different sources that tackle the two variables being studied in this study - the Self-Esteem (Independent Variable) and Distress Tolerance (Dependent Variable).

\section{Self-Esteem}

Social Scientists commonly believed that every human person has the basic drive to feel good about one's image and must enhance and maintain this positive self-concept to become better persons (Pyszczynski, Greenberg, Solomon, Arndt \& Schimel, 2004). This optimistic view of one's self is best known as Self-Esteem. Self-esteem, as defined by Leary and MacDonald (2003) is the "overall personal evaluation or attitude toward oneself." Morris Rosenberg, the maker of Rosenberg Self-Esteem Scale (RSES), defined this term as "a personal worth or worthiness" (Baumeister, Roy, Smart, \& Boden, 1996). However, scholars disagree with each other concerning the nature of this psychological construct. Regardless of this disagreement, they all agree that self-esteem refers to a positive evaluation of oneself (Leary \& MacDonald, 2003).

Self-esteem, according to Gecas and Schwalbe (1983), is composed of two distinct dimensions - the competence and worth. The competence dimension is the extent to which human beings see their potential and efficacy. The second dimension which is "worth" is the degree to which humans feel they are valuable persons (Cast and Burke, 2002).

According to Rokba (2013), self-esteem has three categories that are sometimes confused or interchanged by some researchers. These three categories are Global Self-esteem or Trait Self-Esteem, State SelfEsteem or Feelings of Self-Worth and Domain Specific Self-Esteem or SelfEvaluations.

Global Self-Esteem is a personality construct that represents how people generally feel about their personal value. It is an overall self-attitude present in all aspects of people's lives and relatively endures across time and situations (Rokba, 2013). Harter (1993) summarized the meaning of global self-esteem as "the overall aggregated opinion of oneself at any one time, on a scale between negative and positive.

The second category is State of Self-Esteem or Feelings of SelfWorth. It is used to refer to self-evaluative emotional reactions to valenced events (i.e. events/situations that are either positive or negative). When people talk about experiences that threaten or boost their self-esteem, they are referring to State Self-Esteem. For example, someone might say his 
self-esteem was very high after receiving a reward, or he might say his self-esteem declined after a depressing event (Brown and Marshall, 2006). Following the footsteps of William James, it is defined as feelings of selfworth. Self-worth is expressed through a sense of pride and pleasure in oneself (positive valence) or feeling of humiliation and shame of oneself (negative valence).

The third category of self-esteem is the Domain Specific Self-Esteem or Self-Evaluations. It refers to how individuals appraise their abilities and attributes. A good example for this is a student who doubts his scholastic ability may be said to have low academic self-esteem while a person who is optimistic in sports may be said to have high athletic self-esteem. Domain Specific Self-Esteem is sometimes interchanged with self-evaluations or self-appraisals, as both of them mean how people do evaluation or appraisal of their physical features, personality characteristics, and abilities. From this perspective, it can be said that people have varying levels of self-esteem in different aspects. Some persons could have high reasoning self-esteem but low numerical self-esteem, while other people could have high athletic self-esteem but low academic self-esteem.

As explained, self-esteem is used in different ways by different researchers. Brown and Marshall (2006) believed that the disagreement and confusion among them in the past is due to lack of consensus regarding the construct itself. They concluded, these three categories are "theoretically distinct and have varied developmental antecedents and consequences." They pointed out that not one of these constructs is most important, only that they should not be used interchangeably. They based this recommendation on evidence that thinking you are good at things is not the same as having high self-esteem (Brown and Marshall, 2006).

\section{Distress Tolerance}

Distress, which may be the result of cognitive and physical processes, is often characterized by striving toward distress alleviation. Simons and Gaher (2005) classified Distress Tolerance (DT) as a "meta-emotion construct." Meta-emotion is "an individual emotion that a person has about his own emotions" (Jäger and Bartsch, 2006).

According to Simons and Gaher (2005), Distress Tolerance (DT) has four dimensions. These are tolerance, absorption, appraisal, and regulation. The Dimension of Tolerance refers to the degree to which human beings perceive an ability to tolerate stressful event. Absorption Dimension 
represents an individual feeling consumed by negative emotions. Appraisal Dimension represents an individual's assessment of distress tolerance. The Dimension of Regulation represents the urgency that an individual feels compelled to do something to alleviate the negative emotion (Migliore, 2010).

Individuals with low distress tolerance see distress as unbearable and describe feeling very upset or distressed. They are ashamed of the distress, unwilling to accept it and have the illogical belief that their coping resources are inferior to others. They work very hard to shun feeling distressed, and if unable to reduce it, they would report feeling overwhelmed by the experience which would compromise their functionality (Simons and Gaher, 2005).

The following relevant studies were collected from different research studies to present a balanced view of the topic studied.

According to Baumeister, Heatherton, \& Tice (1993), self-esteem continues to be one of the topics of interest of psychology researchers. However, this concept also sparked the interest of some criminology researchers who studied about juvenile delinquents (Cheng, 2014). Selfesteem is regarded by numerous psychologists (e.g., Carl Rogers, Abraham Maslow, Sigmund Freud) in their theories as one of the essential human needs (Greenberg, Solomon, Pyszczynski, Rosenblatt, Burling, Lyon \& Pinel,1992).

Having high self-esteem is beneficial to those who possess such: they feel good about themselves, they can cope effectively with challenges and negative comments, and they live in a social world in which they believe that people value and respect them. Although having very high self-esteem has negative consequences, most people with high self-esteem appear to lead happy and productive lives (Baumeister et al., 1993). By contrast, people with low self-esteem see the world through a more negative lens, and their general dislike for themselves colors their perceptions of everything around them.

The effect of low self-esteem on depression has also been found in some Adolescents. Using data from a large representative sample, the researcher found that self-esteem scores in early adolescence (ages 11 to 15) predicted depression at age 26 , controlling for adolescent depression, sex, and socioeconomic status Trzesniewski et al., (2006).

Simons and Gaher (2005), who defined distress tolerance as the ability to tolerate negative emotional states, said, the inability to tolerate negative emotional states, affect one's appraisal of and emotion regulation strategies 
used in response to negative affective states. They posited that an individual with low levels of distress tolerance are more likely to negatively evaluate and appraise a situation due to the belief that they are unable to tolerate negative distress, which, in turn, will lead to maladaptive emotion regulation strategies (e.g., avoidance).

This study revealed that self-esteem and distress tolerance are both psychological constructs that have a strong relationship with mental health and behavior. Based on the researchers' belief, studying the correlation of Self-Esteem and Distress Tolerance of Criminology students at the University of Bohol would be the first-ever conducted research in the province and probably in the whole country.

This study aimed to determine the self-esteem level and degree of distress tolerance of Criminology Students of the University of Bohol.

\section{RESEARCH METHODOLOGY}

This is a descriptive-quantitative research utilizing two standardized tools that were validated in various studies. These questionnaires are the following: (1) Rosenberg Self-Esteem Scale to determine the level of self-esteem of the respondents and (2) Distress Tolerance Scale to gauge the respondents' degree of tolerance or ability to withstand negative affect or other aversive psychological and/or physical states.

The respondents of this study were 240 selected students from the University of Bohol who were enrolled in the Criminology program in the first semester of academic year 2015-2016 using purposive sampling.

This study was conducted at the College of Criminology of the University of Bohol. Specifically, the research locale was at the 3rd Floor of the Science and Technology (ST) Building, Dr. Cecilio Putong St. Tagbilaran City, Bohol.

As to the profile of the respondents, $122(50.83 \%)$ respondents were 18 to 20 years old, $58(24.17 \%)$ were $15-17$ years old, $47(19.58 \%)$ were 21 to 23 years old, $11(4.58 \%)$ were $24-26$ years old, and two $(0.83 \%)$ were in the age range of 27 and above.

The sex of the respondents was equally distributed with the frequency of 120 males (50\%) and 120 females (50\%) from the first year to fourth year level. Samples from each year level were equally distributed from the total number of respondents which was 240 . Out of these 240 respondents, each year level had 60 respondents (25\%) from the total population. 
This study used two standardized tools, namely: Rosenberg SelfEsteem Scale and Distress Tolerance Scale. Permission on the use of these tools was obtained prior to conducting the study. The Rosenberg Self-Esteem Scale was a 10-item test that measures global self-worth by measuring both positive and negative feelings about the self. This scale is believed to be uni-dimensional. All items were answered using a 4-point Likert scale format ranging from 'Strongly Agree' to 'Strongly Disagree.' The Distress Tolerance Scale is a 15 item self-report measure of emotional distress tolerance developed by Simons and Gaher (2005) to measure individual differences in the capacity of distress tolerance or ability to withstand negative pressures.

As follows were the Scoring System and Score Interpretations that were used in the study.

\section{Rosenberg Self-Esteem Scale Scoring System:}

The respondents rated each item on a 4-point Likert scale: 1 (Strongly Disagree), 2 (Disagree), 3 (Agree), and 4 (Strongly Agree). The equivalent scores of the items were all added to get the final figures that represented the level of self-esteem of the respondent.

Items 2, 5, 6, 8, 9 are reverse scored. Give Strongly Disagree 1 point, Disagree 2 points, Agree 3 points, and Strongly Agree 4 points. Sum scores for all ten items. Keep scores on a continuous scale. Higher scores indicated higher self-esteem.

\section{Distress Tolerance Scale}

1. The respondents rated each item on a 4-point Likert scale: 1 (Strongly Agree), 2 (Agree), 3 (Disagree), and 4 (Strongly Disagree). The equivalent scores of the items were all added to get the final figures that represented the degree of distress tolerance of the respondent.

2. There was one total scale, and only item 6 was reversely coded.

A formal written permission/endorsement was secured from the Dean of the College of Criminology of the University of Bohol to allow the researchers to conduct the study. After securing the necessary permit and the roster of students of the entire department, the questionnaires were distributed personally by the researchers to the respondents. 
To ensure the ethical considerations, the researchers secured consent from the respondents with the assurance of maintaining the complete anonymity of data handling. The responses were then tallied and collated; Frequencies, percentages, weighted mean, Pearson Product Moment Correlation were used to analyze the data.

\section{RESULTS AND DISCUSSION}

This study was conducted by using two validated standardized tools, namely: (1) Rosenberg Self-Esteem Scale (RSES) which measured the global self-esteem, and the (2) Distress Tolerance Scale (DTS) which measured the respondents' ability to withstand negative pressure.

\section{Self-Esteem and Distress Tolerance of the Respondents}

Table 1. Self-esteem and distress tolerance of the respondents

\begin{tabular}{|l|l|l|l|l|l|l|}
\hline Year Level & Self-Esteem & Distress Tolerance & & & & \\
\hline & Score & Description & Rank & Score & Description & Rank \\
\hline First Year & 2.7 & High & 3 & 2.3 & Low & 1.5 \\
\hline Second Year & 2.8 & High & 2.5 & 2.3 & Low & 1.5 \\
\hline Third Year & 2.8 & High & 2.5 & 2.3 & Low & 2.5 \\
\hline Fourth Year & 2.9 & High & 1 & 2.3 & Low & 2.5 \\
\hline Total & 11.2 & & & 9.2 & & \\
\hline Mean & 2.8 & HIGH & & 2.3 & LOW & \\
\hline
\end{tabular}

\section{Overall Self-Esteem and Distress Tolerance of the Respondents}

Self-Esteem. Table 1 shows that the fourth year respondents had the highest level of self-esteem among the four year levels obtaining a score of 2.9 with an interpretation of High Self-Esteem. Next, were the second year and third year respondents who obtained a score of 2.8 with a descriptive meaning of High Self-Esteem. Lastly, the first year respondents attained 2.7 with an interpretation of High Self-Esteem. Overall, the respondents of this study obtained an average score of 2.8 which means the Criminology students of University of Bohol possessed High level of Self-Esteem.

Distress Tolerance. All year levels had a Low Distress Tolerance with a mean of 2.3. 
Table 2. Relationship of self-esteem and distress tolerance of the respondents

\begin{tabular}{|l|l|l|l|}
\hline Computed Pearson $r$ & $p$-value & Decision & Interpretation \\
\hline 0.997333 & 0.002667 & Ho: Reject & Significant \\
\hline
\end{tabular}

\section{Correlation of Self-Esteem and Distress Tolerance}

Table 2 presents the relationship between the Self-Esteem and Distress Tolerance of the respondents. The computation in the Pearson Moment Correlation Coefficient resulted in an $r$ value of 0.997333 . Using an online Pearson calculator, it resulted to a p-value of 0.002667 which was lesser than 0.05 confidence level $(p<0.05)$; hence, the result was significant, and the decision was to reject the null hypothesis. This result meant that there was a significant relationship between the two variables. The respondents' self-esteem influenced the students distress tolerance and vice-versa when the self-esteem increased, the distress tolerance rose as well.

\section{CONCLUSION}

The respondents of this study possessed High Self-Esteem which indicated normalcy in self-evaluation or self-perception.

The Criminology students had Low Distress Tolerance. Their ability to withstand stress and adversities was below normal. This result implied that they had a hard time overcoming or managing distress or negative situations due to pessimism.

There was a significant and direct relationship between self-esteem and distress tolerance.

\section{RECOMMENDATIONS}

Anchored on the preceding conclusions, the following recommendations were offered:

1. Since the respondents possessed High Self-Esteem, it is recommended that this aspect among the respondents be maintained and enhanced through Values Enhancement Seminars.

2. The respondents possessed Low Distress Tolerance based on the result of the Distress Tolerance Scale (DTS). With this finding, the researchers recommend that another psychometric tool be used 
to further assess their ability to withstand negative situations. The researchers are encouraging the College of Criminology to connect with the Guidance Center to address this issue.

3. Since there was a correlation between the two variables studied in this study, it is strongly recommended that a replication of this study be conducted to check whether the result was a one-time occurrence.

\section{REFERENCES CITED}

Adams, S. (2015, January 7). The Most Stressful Jobs of 2015. Retrieved from http://goo.gl/wGvUta, (accessed last 15 October 2015).

Anshel, M.H. (2000). A conceptual model and implications for coping with stressful events in police work. Criminal Justice and Behavior, 27, 375400. Retrieved from https://goo.gl/nJFLk3, (accessed last 15 October 2015).

Baumeister, R. F., Heatherton, T. F., \& Tice, D. M. (1993). When ego threats lead to self-regulation failure: negative consequences of high self-esteem. Journal of personality and social psychology, 64(1), 141. Retrieved from http://goo.gl/ScWE3O (accessed last 10 October 2015).

Baumeister, Roy F.; Smart, L.; Boden, J. (1996). "Relation of threatened egotism to violence and aggression: The dark side of selfesteem". Psychological Review 103 (1): 5-33. doi:10.1037/0033295X.103.1.5. PMID 8650299. Retrieved from https://goo.gl/8A9LG5, (accessed last 10 October 2015).

Brown, J. D., \& Marshall, M. A. (2006). The three faces of self-esteem. Selfesteem issues and answers: A sourcebook of current perspectives, 4-9. Retrieved from http://goo.gl/jBvmXD (accessed last 10 October 2015).

Burke, R.J. (1993). Work-family stress, conflict, coping and burnout in police officers. Stress Medicine, 9(3), 171-180.

Cast, A. D., \& Burke, P. J. (2002). A theory of self-esteem. Social forces, 80(3), 1041-1068. Retrieved from http://goo.gl/WhxF4I (accessed last 10 October 2015). 
Cheng, C. (2014). The Predictive Effects of Self-Esteem, Moral Self, and Moral Reasoning on Delinquent Behaviors of Hong Kong Young People. International Journal of Criminology and Sociology, 3, 133-145. Retrieved from http://goo.gl/3QjTx6 (accessed last 10 October 2015).

Crank, J.P., and Caldero, M., (1991), "The Production of Occupational Stress in Medium-sized Police Agencies: A Survey of Line Officers in Eight Municipal Departments", Journal of Criminal Justice, Vol. 19, pp. 339-349. Retrieved from https://goo.gl/bZjp3X, (accessed last 29 December 2015).

Elias, S. M. (Ed.). (2013). Deviant and criminal behavior in the workplace. NYU Press. Retrieved from https://goo.gl/ARJV9T (accessed last 22 November 2015).

Gecas, V., \& Schwalbe, M. L. (1983). Beyond the looking-glass self: Social structure and efficacy-based self-esteem. Social psychology quarterly, 77-88. Retrieved from http://goo.gl/u8tLYI (accessed last 10 October 2015).

Greenberg, J., Solomon, S., Pyszczynski, T., Rosenblatt, A., Burling, J., Lyon, D., ... \& Pinel, E. (1992). Why do people need self-esteem? Converging evidence that self-esteem serves an anxiety-buffering function. Journal of personality and social psychology, 63(6), 913. Retrieved from http:// goo.gl/EjaHpV (accessed last 6 October 2015).

Harter, S. (1993). Causes and consequences of low self-esteem in children and adolescents. In Self-esteem (pp. 87-116). Springer US. Retrieved from http://goo.gl/M75WNw (accessed last 10 October 2015)

Jäger, C., \& Bartsch, A. (2006). Meta-emotions. Grazer Philosophische Studien, 73(1), 179-204. Retrieved from http://goo.gl/sFwtQ7 (accessed last 10 October 2015).

Leary, M. R. \& MacDonald, G. (2003). Individual differences in trait selfesteem: A theoretical integration. In M. Leary and J. Tangney (Eds.), Handbook of self and identity (pp. $401-418$ ). New York: Guildford Publications. Retrieved from https://goo.gl/LgR6WM (accessed last 15 October 2015). 
Marcia, J.E., Waterman, A.S., Matteson, D.R., Archer, S.L. and Orlofsky, J.L. (1993) Ego Identity: A Handbook for Psycho-social Research. Springer, New York.

Maslow, A. H. (1987). Motivation and Personality (Third ed.). New York: Harper \& Row. ISBN 0-06-041987-3.

Migliore, D. A. (2010). Predictors of binge eating: perfectionism, distress tolerance and eating self-efficac (Doctoral dissertation, Rutgers University-Graduate School-Newark). Retrieved from https://goo.gl/ qkzfcd (accessed last 10 October 2015).

Pyszczynski, T., Greenberg, J., Solomon, S., Arndt, J., \& Schimel, J. (2004). Why do people need self-esteem? A theoretical and empirical review. Psychological bulletin, 130(3), 435. Retrieved from http://goo.gl/1hpGgy (accessed last October 10, 2015).

Rokba, M. Z. A., Anwar, A. A., \& Abed, Y (2013). Relationship between Mental Health and Self Esteem Among Mothers of Children with Mental Disability in Gaza Governorates. Retrieved from http://goo.gl/tcyDJ5 (accessed last 10 October 2015).

Simons, J. S., \& Gaher, R. M. (2005). The Distress Tolerance Scale: Development and validation of a self-report measure. Motivation and Emotion,29(2), 83-102. Retrieved from http://goo.gl/0STQOI (accessed last 10 October 2015).

Sylvester, Phil (2015). Crime \& Scams in the Philippines: watch out for these! World Nomads. Retrieved from http://goo.gl/0q3rkd (accessed last 3 October 2015).

Tan, L. (2015). How to avoid falling prey to "tanim bala" scheme. Retrieved from http://goo.gl/qbU0Ko, (accessed last 15 November 2015).

Trzesniewski, K. H., Donnellan, M. B., Moffitt, T. E., Robins, R. W., Poulton, R., \& Caspi, A. (2006). Low self-esteem during adolescence predicts poor health, criminal behavior, and limited economic prospects during adulthood. Developmental psychology, 42(2), 381. Retrieved from http://goo.gl//hdwtz (accessed last 21 November 21 2015). 
Waterman, A. S. (1988). Identity status theory and Erikson's theory: Communalities and differences. Developmental Review, 8(2), 185-208. Retrieved from http://goo.gl/RBPKEX (accessed last 23 November 2015). 